\title{
Mapping vanished mountain shapes \\ —The struggle between limestone mining and establishing a natural park at Mount Bukō-
}

\author{
Hiroko Toyota $^{\mathrm{a}, *}$, Daiki Ito ${ }^{\mathrm{a}}$, Shuya Suzuki ${ }^{\mathrm{a}}$, Ryohei Hara ${ }^{\mathrm{a}}$, Wang Junxiang ${ }^{\mathrm{a}}$ \\ ${ }^{a}$ Graduate School of Humanities and Social Sciences, University of Tsukuba.s1630022@u.tsukuba.ac.jp, \\ likefrontier_1590@yahoo.co.jp,mk350s1102@gmail.com,miyako.higawa@me.com,junxiang602@qq.com \\ * Corresponding author
}

Keywords: Japanese view of beauty and nature, The transformation of a mountain’s shape, Chichibu City

This report searches for the Japanese view of beauty and nature through a study of the mapping of the transformation of a mountain's shape. A normal map primarily intends to express existing shapes, but this report maps the vanished shape of a mountain from the limestone mining of its slopes. This is done to consider how its vanished shape has impacted the Japanese view of beauty and nature. The mountain studied is Mount Bukō located in Chichibu City and Yokozemachi in Saitama Prefecture. Mount Bukō is suitable for limestone mining, and during the Edō Period, limestone was mined on this mountain to obtain material for mortar and fertilizer. In the Meiji Period, cement was used in Japan to construct buildings and surface roads, and limestone (raw material for cement) was produced and consumed in large quantities. During the Taishō Period, corporations started to mine vast quantities of limestone. At Mount Bukō, the shape of the mountain was heavily transformed by limestone mining (Figure1,2).

However, during the 1940s, Mount Bukō was mentioned as a candidate site for a national park. In 1957, the entire area_-including the mining site-was designated the Saitama Prefectural Natural Park. Parks are designated in Japan in imitation of Europe and America, and their major purposes are to preserve beautiful scenery and serve as places for residents' recreational activities. Thus, by the Meiji Period, national parks such as Nikko National Park (which includes the Tōshōgū Shrine) were already being designated. Considering the above historical background, the movement to designate Mount Bukō as a park can be understood as an effort to preserve its scenery and provide a place for residents' activities. But limestone mining continues to transform the shape of the mountain as, for example, a total of roughly 6.99 million tons of limestone were mined on Mount Bukō in 2016. By analyzing the facts of this case, this study can portray the Japanese consciousness of the change of the shapes of mountains and clarify the nature of their view of beauty and nature in mountains.

This paper reports on the preparation of a stereoscopic map based on topographical maps and photos created since the start of the Meiji Period, Chichibu fudasho temple drawings from the Edō Period, and the chronological mapping of the shape of the mountain before and since its designation as a park. Mapping using diverse source materials to represent exposed rock and landslides caused by limestone mining permits a detailed study that would be impossible based on topographical maps lacking contour lines, photographs, or drawings from one direction, primarily from the northern side of the mountain (Figure3,4). This study shows which parts of the disappearing Mount Bukō are important to people and which parts of the remaining mountain shape they value highly. It also portrays the Japanese view of beauty and nature from a cultural perspective to aesthetically evaluate artificially formed "nature" as seen in temple gardens or bonsai.
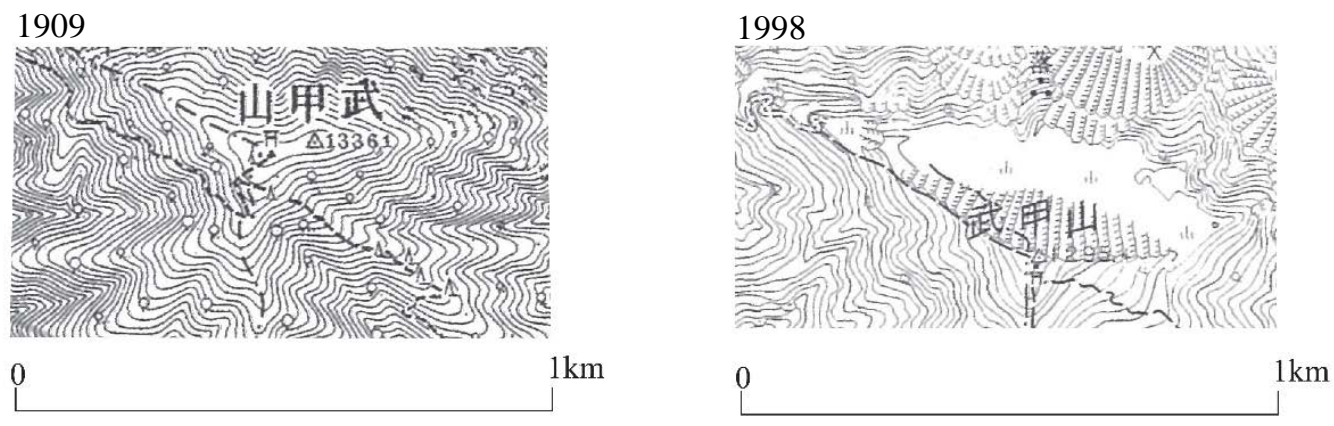

Figure 1. Topographic map of the summit of Mount Bukō-1909 and 1998-

Map 50000 Chichibu published by Geographical Survey Institute. 


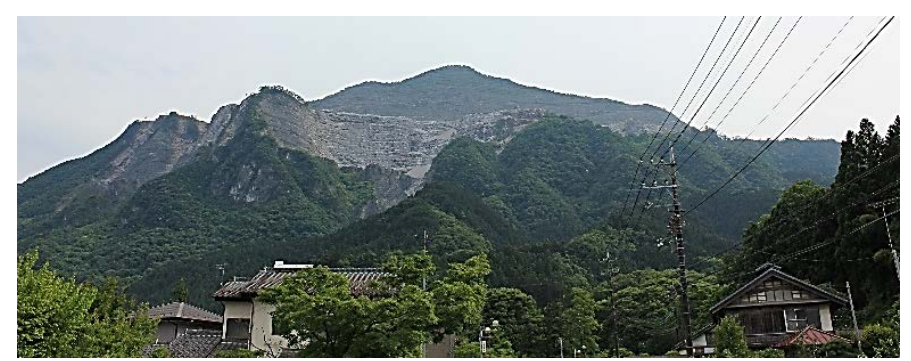

Figure 2. Mount Bukō.

Shuya Suzuki took in 2018.

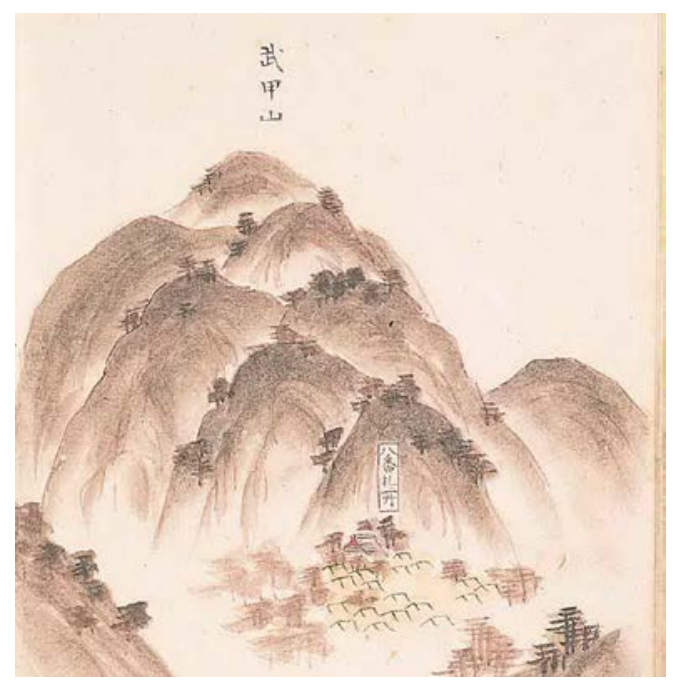

Figure 3. Drawing of Mount Bukō in Edo period.

Takemura Ritsugi (1823) Chichibu-Junpaiki.

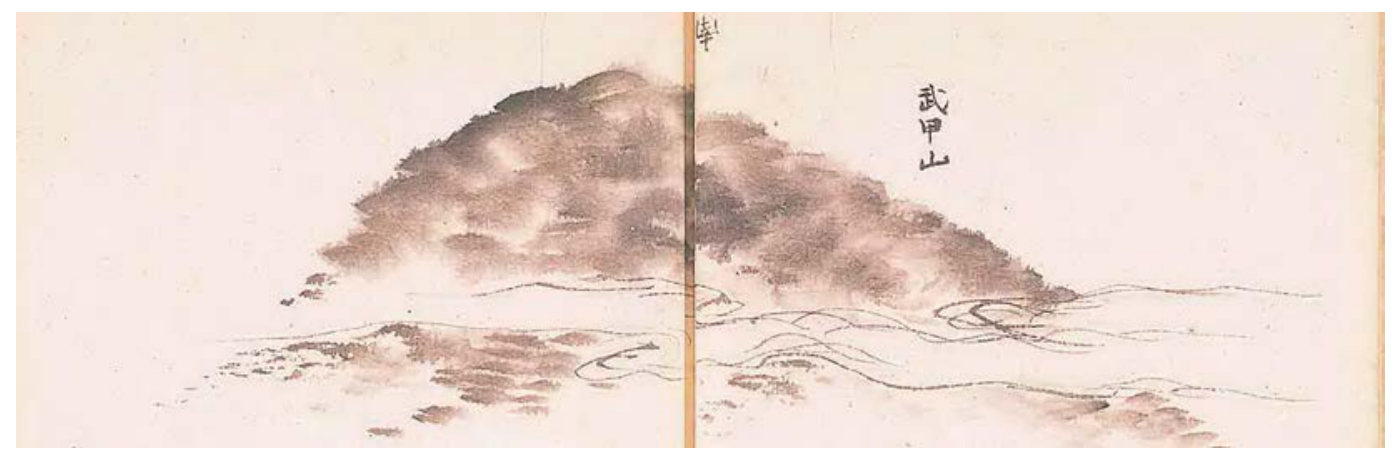

Figure 4. Drawing of Mount Bukō in Edo period.

Watanabe Shoen(1853) Chichibu-Nikki. 